\title{
Changes in serum indoxyl sulfate levels after acute myocardial infarction and the correlation with kidney injury: an observational study
}

Shuhei Watanabe ${ }^{1}$, Hideki Fujii ${ }^{*}$, Keiji Kono ${ }^{1}$, Kentaro Watanabe ${ }^{1}$, Shunsuke Goto ${ }^{1}$, Susumu Sakamoto ${ }^{2}$ and Shinichi Nishi ${ }^{1}$

\begin{abstract}
Background: Kidney function after acute myocardial infarction (AMI) correlates with patient prognosis. Several studies reported the role that indoxyl sulfate (IS), a uremic toxin, plays in the progression of chronic kidney disease and cardiovascular diseases. This study aims at investigating the serum IS level changes after AMI and their correlation with kidney injury.

Methods: In this observational study, twenty consecutive patients with AMI who received percutaneous coronary intervention within $2 \mathrm{~h}$ after admission were enrolled. We measured serum IS levels on admission (day 1) and day 2-3 and evaluated their clinical characteristics. Further, we measured serum neutrophil gelatinase-associated lipocalin (NGAL) levels at admission as a marker of kidney injury.

Results: Although estimated glomerular filtration rate (eGFR) decreased at day 2-3 compared to that at day 1 , serum IS levels at day 1 were rather higher than those at day $2-3$. Further analysis only among patients with preserved kidney function revealed that serum IS levels at day 1 were significantly higher than those at day 2-3, despite a higher eGFR. Additionally, serum NGAL levels at admission were higher in these patients than in healthy subjects. Further, serum NGAL levels were significantly higher in patients with higher serum IS levels compared to those with lower IS levels.
\end{abstract}

Conclusion: This study suggests that pathophysiological conditions in patients with AMI may elevate serum IS levels independent of kidney dysfunction and that IS may be one of the contributory factors related to kidney injury in AMI.

Keywords: Indoxyl sulfate, Acute myocardial infarction, Kidney injury

\section{Background}

Chronic kidney disease (CKD) is one of the crucial risk factors for cardiovascular disease (CVD); the association between CKD and CVD is termed as "cardiorenal syndrome." Several studies have reported higher CVD incidences including coronary artery disease, atrial fibrillation, heart failure, stroke, and peripheral arterial disease in CKD patients than in the general population

\footnotetext{
* Correspondence: fhideki@med.kobe-u.ac.jp

'Division of Nephrology and Kidney Center, Kobe University Graduate School of Medicine, 7-5-2, Kusunoki-cho, Chuo-ku, Kobe, Hyogo 650-0017, Japan Full list of author information is available at the end of the article
}

$[1,2]$. CKD is a risk factor for CVD, and in turn, CVD is also a risk factor for CKD and acute kidney injury (AKI). Reports suggest that myocardial infarction (MI) complicates kidney dysfunction in approximately $20 \%$ of patients [3] and that kidney function after MI predicts patient prognosis $[4,5]$. Although the importance of kidney function preservation was recognized after CVD, the detailed mechanisms of "cardiorenal association" remain unclear. Particularly, research offers very little explanation of the mechanisms of CVD-caused kidney injury.

Indoxyl sulfate (IS) is a protein-bound uremic toxin, which is metabolized from tryptophan and accumulates

(c) The Author(s). 2019 Open Access This article is distributed under the terms of the Creative Commons Attribution 4.0 International License (http://creativecommons.org/licenses/by/4.0/), which permits unrestricted use, distribution, and 
with progression of kidney dysfunction. Furthermore, IS causes interstitial fibrosis and glomerular sclerosis and contributes to progression of kidney dysfunction $[6,7]$. Some studies have reported that IS is related not only to progression of CKD, but also to CVD. IS causes proliferation, hypertrophy, fibrosis, and calcification of vascular smooth muscle cells [8-10]. These facts suggest that IS is one of the crucial factors related to cardiorenal syndrome. Additionally, we recently reported that acute myocardial infarction (AMI) model rats exhibited higher serum IS levels compared to control rats, although the kidney function between the two groups was comparable. Our data suggested that the elevation of serum IS levels after AMI may be accountable for kidney injury. Furthermore, the administration of AST-120, an adsorptive agent of IS, ameliorated intrarenal injury because of decrease in the serum IS levels and urinary IS excretion in the experimental study [11].

To date, no clinical study has investigated serum IS level changes after AMI and examined its relationship with kidney injury. The present study investigates serum IS levels before and after coronary intervention in patients with AMI and its relationship with clinical factors and kidney injury.

\section{Methods}

\section{Study population and procedures}

In this observational study, 20 consecutive patients who were diagnosed with AMI and underwent percutaneous coronary intervention (PCI) within $2 \mathrm{~h}$ of visiting the Akashi Medical Center (Akashi, Japan) between October 2014 and April 2016 were enrolled. Iodinated contrast media was used in all procedures in this study. Patients with pressor agent administration to maintain appropriate hemodynamics during the hospitalization, coronary artery bypass graft surgery, severe valvular disease requiring treatment, infectious disease, collagen disease, and malignancy were excluded. Furthermore, patients whose kidney function was CKD stage 5 and 5D and whose data were not available were excluded from the study.

AMI was defined as the detected elevation of serum cardiac biomarker levels, such as cardiac troponin, creatine kinase (CK), or creatine kinase-MB (CK-MB), and demonstrated a new significant ST elevation $\geq 0.1 \mathrm{~mm}$ on electrocardiogram, and/or typical ischemia symptom such as chest pain and dyspnea [12]. Coronary angiography revealed intracoronary thrombus in at least a single coronary area. The presence of a CVD history was determined on the basis of history taking and clinical records. Diabetes mellitus was defined as a casual blood glucose level $\geq 200 \mathrm{mg} / \mathrm{dL}$, HbA1c (National Glycohemoglobin Standardization Program [NGSP]) $\geq 6.5 \%$, and/or use of antidiabetic medications (insulin or oral hypoglycemic agents). Hypertension was defined as a history of hypertension and/or use of antihypertensive drugs. Hyperlipidemia was defined as a low-density lipoprotein cholesterol level $\geq 140 \mathrm{mg} / \mathrm{dL}$ and/or the use of statins.

We conducted serum IS level measurements and other biochemical tests on admission before PCI (day 1) and day $2-3$. We evaluated serum IS level changes and assessed the relationship of serum IS levels with clinical factors. In addition, we examined the relationship between serum IS level changes and estimated glomerular filtration rate (eGFR) to confirm the association of its change with kidney function. Furthermore, these evaluations were conducted only in patients with eGFR $\geq 60$ $\mathrm{mL} / \mathrm{min} / 1.73 \mathrm{~m}^{2}$. To ascertain normal serum IS levels, we also measured serum IS levels in 5 healthy volunteers. Finally, we investigated the relationship of serum neutrophil gelatinase-associated lipocalin (NGAL) levels with serum IS levels and other clinical factors.

\section{Serum measurements}

Venous blood was collected from patients on admission before PCI and day 2-3. Laboratory tests were conducted using standardized clinical laboratory methods, and remainder serum samples were stored at $-80^{\circ} \mathrm{C}$ until analysis. eGFR was calculated using J-MDRD (modified for Japanese) equation: eGFR $=194 \times($ serum creatinine $)^{-1.094} \times(\text { age })^{-0.287} \times(0.739$ if female $)$ [13]. Serum IS levels were evaluated using high-performance liquid chromatography (Fushimi, Tokyo, Japan). In addition, we evaluated serum NGAL levels at day 1 using a commercially available assay (Antibody Shop, Gentofte, Denmark). All the values of normal healthy subjects were obtained from a previously published report [14].

\section{Statistical analysis}

Data were analyzed using the IBM SPSS statistics version 23.0 (SPSS Inc., Chicago, IL, USA). Values are summarized using proportions, mean $\pm \mathrm{SD}$, or medians and interquartile range depending on the normality or nonnormality of the data distribution. Data distribution was evaluated using the Kolmogorov-Smirnov test. Data at day 1 and day 2-3 were compared using a Wilcoxon signed-rank test. The Mann-Whitney $U$ test was used to compare variables between two groups. The correlation of the study variables was evaluated using Spearman rank test. To determine the independent factors correlated to serum IS levels, we performed a multivariate analysis including age and kidney function. Furthermore, $P<0.05$ was considered statistically significant.

\section{Results}

Patient characteristics

Table 1 presents the characteristics of enrolled patients on admission. In the present study, the mean eGFR 
Table 1 Patient characteristics

\begin{tabular}{ll}
\hline & $(n=20)$ \\
\hline Age (years) & $68 \pm 12$ \\
Sex (male/female) & $15 / 5$ \\
Smoking (\%) & $12(60)$ \\
History of CVD (\%) & $3(15)$ \\
Diabetes mellitus (\%) & $12(60)$ \\
Systolic blood pressure (mmHg) & $126.9 \pm 24.3$ \\
Diastolic blood pressure $(\mathrm{mmHg})$ & $74.4 \pm 15.3$ \\
eGFR (mL/min/1.73 m²) & $71.6 \pm 25.1$ \\
Indoxyl sulfate ( $\mu \mathrm{g} / \mathrm{mL})$ & $0.56[0.32-0.93]$ \\
Max CK (U/L) & $1924.0[719.5-3067.0]$ \\
Max CK-MB (U/L) & $207.5[74.3-300.0]$ \\
NT-pro BNP (pg/mL) & $159.0[33.3-1610.0]$ \\
Dose of contrast media (mL) & $190.7 \pm 52.5$ \\
LVEF (\%) & $53.1 \pm 11.3$ \\
Antiplatelet agent (\%) & $1(5)$ \\
Statin (\%) & $4(20)$ \\
Ca-blocker (\%) & $4(20)$ \\
RAS-I (\%) & $5(25)$ \\
$\beta$-blocker (\%) & $0(0)$ \\
\hline BMI body mass index CVD cardiovasclar disease &
\end{tabular}

$B M I$ body mass index, CVD cardiovascular disease, eGFR estimated glomerular filtration rate, $C K$ creatine kinase, NT-pro BNP N-terminal pro-B-type natriuretic peptide, $L V E F$ left ventricular ejection fraction, $C a$-blocker calcium channel blocker, RAS-I renin-angiotensin system inhibitor

value at day 1 was $71.6 \pm 25.1 \mathrm{~mL} / \mathrm{min} / 1.73 \mathrm{~m}^{2}$ and total 14 patients $(70.0 \%)$ demonstrated eGFR $>60 \mathrm{~mL} / \mathrm{min} /$ $1.73 \mathrm{~m}^{2}$. The maximum $\mathrm{CK}$ and CK-MB levels were $1924.0[719.5-3067.0]$ and 207.5 [74.3-300.0] IU, respectively. The left ventricular ejection fraction after PCI was $53.1 \pm 11.3 \%$. The mean used dose of contrast media was $190.7 \pm 52.5 \mathrm{~mL}$, which did not widely vary among patients. Further, the mean amount of fluid infusion was $2825.0 \pm 494.0 \mathrm{~mL}$.

\section{Changes in kidney function and serum indoxyl sulfate levels}

Figure 1a shows eGFR decrease at day 2-3 compared to that at day $1(72.8[49.0-93.6]$ to $70.4[50.4-85.8] \mathrm{mL} /$ $\mathrm{min} / 1.73 \mathrm{~m}^{2}, P<0.05$; Fig. 1a). However, serum IS levels at day $2-3$ also significantly decreased compared to that at day $1(0.56[0.32-0.93]$ to $0.48[0.22-0.76] \mu \mathrm{g} / \mathrm{mL}$, $P<0.05$; Fig. 1 b). Serum IS levels in healthy volunteers were $0.33[0.18-0.44] \mu \mathrm{g} / \mathrm{mL}$. Then, we evaluated these data only in patients with eGFR $\geq 60 \mathrm{~mL} / \mathrm{min} / 1.73 \mathrm{~m}^{2}$ $(N=14)$ for evaluation in patients with comparatively normal kidney function. eGFR significantly decreased at day 2-3 (82.3 [71.9-97.3] to 80.9 [69.5-88.9] $\mathrm{mL} / \mathrm{min} /$ $1.73 \mathrm{~m}^{2}, P<0.05$; Fig. 1c). Furthermore, serum IS levels also significantly decreased at day $2-3(0.45$ [0.28-0.84] to $0.28[0.20-0.62] \mu \mathrm{g} / \mathrm{mL}, P<0.05$; Fig. $1 \mathrm{~d})$. In both groups, no significant relationship between changes in serum IS level and changes in eGFR was observed. Furthermore, there was no significant relationship between changes in serum IS level and total amount of fluid infusion.

\section{Correlation of serum IS levels with clinical factors on admission}

Serum IS levels at day 1 significantly correlated with age $(r=0.548, P<0.05)$ and eGFR $(r=-0.512, P<0.05)$. No significant correlation of serum IS levels at day 1 with the degree of myocardial damage and cardiac function after PCI was observed (Table 2). The results of the multivariate analysis including age and eGFR suggested that age was tended to be correlated with serum IS levels at day 1 $(\beta=0.511, P=0.06)$.

\section{Serum NGAL levels and the relationship with serum IS levels}

We examined serum NGAL levels, a kidney injury biomarker, for evaluating kidney injury on admission. The serum NGAL levels in the patients were 231.0 [162.0371.6] $\mathrm{ng} / \mathrm{mL}$. The levels in our patients were significantly higher than those in normal healthy subjects referring a previous report (35.4 [18.9-46.5] ng/mL) [14]. Serum NGAL levels tended to be correlated with serum IS levels $(r=0.429, P=0.059$; Fig. 2a). Furthermore, when we categorized patients into two groups based on whether serum IS levels were higher than median levels or not, serum NGAL levels were significantly higher in patients with higher serum IS levels compared to those with lower IS levels (Fig. 2b). After the adjustment by eGFR $\geq 60 \mathrm{~mL} / \mathrm{min} / 1.73 \mathrm{~m}^{2}$ or not, serum NGAL levels tended to positively correlate with higher serum IS levels at day $1(\beta=0.469, P=0.065)$.

\section{Discussion}

To the best of our knowledge, this study is the first that evaluates serum IS level changes in patients at acutephase of AMI. The results of this study revealed that serum IS levels significantly decreased at day 2-3 compared to those at day 1 , independent of the kidney function, and serum IS levels tended to correlate with serum NGAL levels at acute phase.

Kidney dysfunction is one of the most crucial complications related to poor prognosis in patients with AMI. The mortality of patients with AMI increases with deterioration of kidney function [4]. Other studies have reported that only $0.3 \mathrm{mg} / \mathrm{dL}$ change in serum creatinine above the baseline during the acute phase of AMI is related to long-term mortality [5]. The mechanisms of kidney injury in AMI are assumed to be multifactorial, for example, decreased arterial perfusion, venous congestion, use of contrast media, inflammation, and so on 

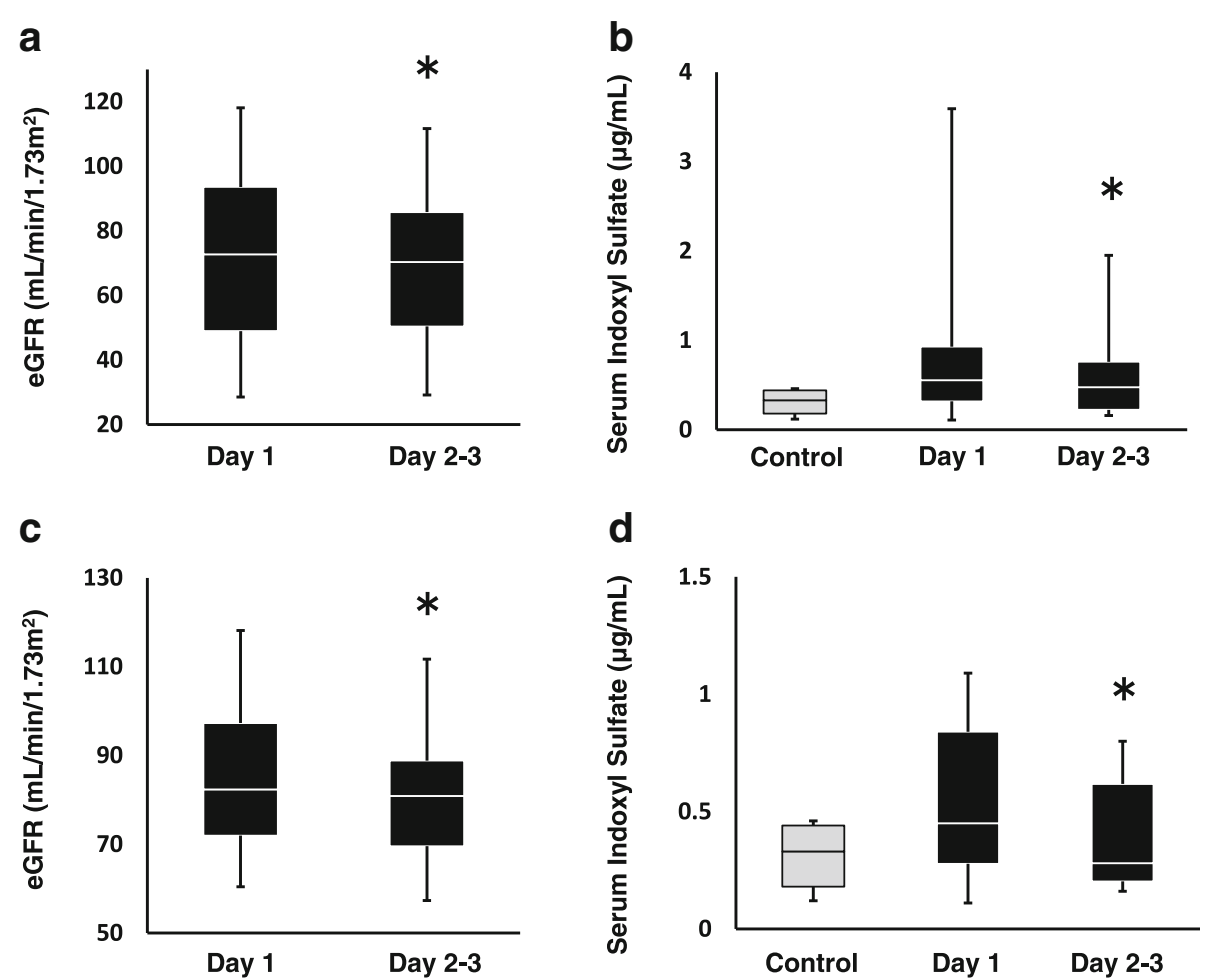

Fig. 1 Changes in kidney function and serum IS levels. a Kidney function at day 1 and day 2-3 in all patients. b Serum IS levels at day 1 and day $2-3$ in all patients. c Kidney function at day 1 and day $2-3$ in patients with eGFR $\geq 60 \mathrm{~mL} / \mathrm{min} / 1.73 \mathrm{~m}^{2}$. $\mathbf{d}$ Serum IS levels at day 1 and day $2-3$ in patients with eGFR $\geq 60 \mathrm{~mL} / \mathrm{min} / 1.73 \mathrm{~m}^{2}$. IS, indoxyl sulfate; eGFR, estimated glomerular filtration rate. ${ }^{*} v$ s. day $1, P<0.05$

[15]. Thus, although kidney function is crucial for patients with AMI, the detailed mechanisms of kidney injury in AMI have not been completely understood.

IS is a uremic toxin that accumulates with deterioration of kidney function and causes progression of kidney and cardiac dysfunction [16]. IS production depends on metabolization of dietary protein to indole by intestinal bacteria, such as Escherichia coli, and SULT1A1

Table 2 Correlation between serum IS levels at day 1 and clinical factors

\begin{tabular}{lll}
\hline & $r$ & $p$ \\
\hline Age & 0.548 & 0.012 \\
BMI & -0.391 & 0.088 \\
Systolic blood pressure & -0.160 & 0.502 \\
Hemoglobin & -0.084 & 0.726 \\
CRP & 0.022 & 0.928 \\
eGFR & -0.512 & 0.021 \\
Max CK & -0.129 & 0.587 \\
Max CK-MB & -0.012 & 0.960 \\
NT-pro BNP & 0.293 & 0.210 \\
LVEF & -0.218 & 0.355 \\
\hline
\end{tabular}

$B M I$ body mass index, CRP C-reactive protein, eGFR estimated glomerular filtration rate, $C K$ creatine kinase, NT-pro BNP N-terminal pro-B-type natriuretic peptide, LVEF left ventricular ejection fraction expression in the liver $[17,18]$. In general, the impaired kidney function in addition to such an increase in the IS production leads to the elevation of serum IS levels [17]. However, a recent report demonstrated that serum IS levels were significantly associated with cardiac dysfunction marker and cardiac event after adjustment for kidney function [19]. Our previous experimental study using the MI model rats demonstrated elevated serum IS levels independent of kidney function and urinary albumin excretions [11]. Furthermore, we demonstrated that kidney injury biomarkers, such as NGAL, kidney injury molecule-1 (KIM-1), and liver-type fatty acidbinding protein (L-FABP), significantly decreased with the administration of AST-120, which reduces IS production. Similarly, other studies have also reported that serum IS levels increased in the MI model rats and that the levels correlated with tissue expression of kidney injury biomarkers, such as KIM-1, in kidney tissues [20]. In addition, the studies also revealed that the administration of AST-120 attenuated kidney fibrosis. These facts suggest that CVD, including MI, may contribute to elevated serum IS levels without any relation to kidney function and that IS could cause kidney injury in CVD.

In the present study, serum IS levels were lower at day 2-3 than those at day 1, although eGFR was lower at day 2-3 compared to that at day1; the IS variation did 

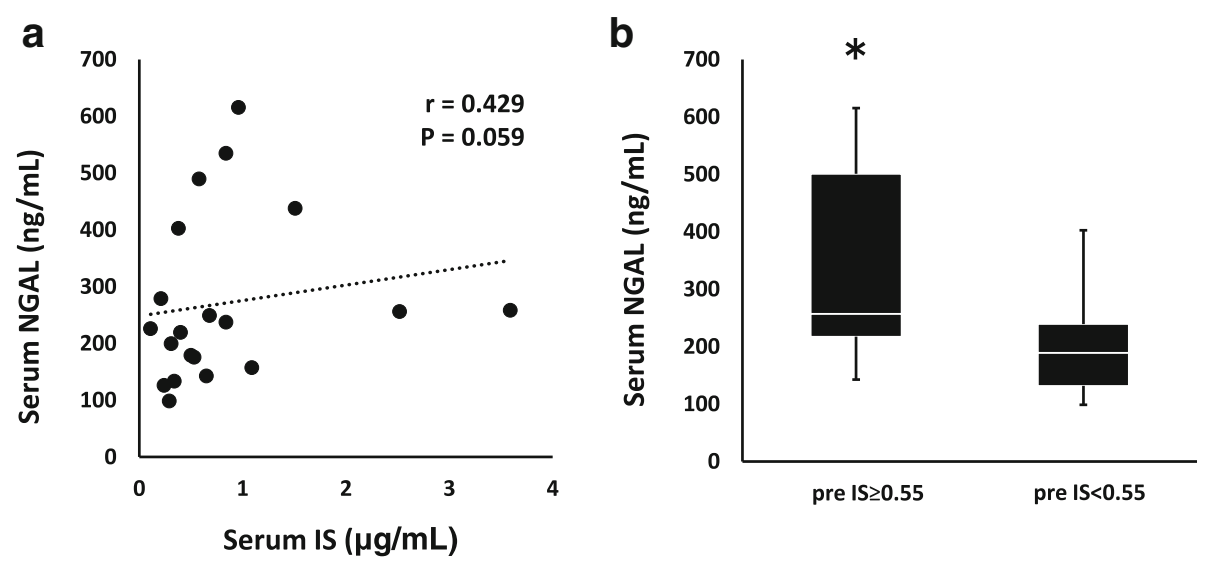

Fig. 2 Relationship between serum NGAL levels and serum IS levels. a Correlation between serum NGAL levels and serum IS levels. b Serum NGAL levels in patients with high and low IS levels. NGAL, neutrophil gelatinase-associated lipocalin; IS, indoxyl sulfate. ${ }^{*}$ Vs. pre-IS $<0.55, P<0.05$. Median IS levels $0.55 \mu \mathrm{g} / \mathrm{mL}$

not correlate with the eGFR variation. This suggested that serum IS levels increased independent of the kidney function in patient with AMI, which corroborate the results of previous experimental studies. Further, our data demonstrated that serum NGAL levels were significantly higher in patients with higher serum IS levels compared to those with lower IS levels and serum NGAL levels tended to correlate with higher serum IS levels after adjustment by kidney function. Therefore, we anticipated that serum IS level elevation might contribute to the worsening of the kidney function in the future, even in the clinical setting. Based on these facts from experimental studies, we hypothesized that lowering serum IS levels could possibly prevent the progression of kidney injury and might improve the prognosis of patients with AMI. AST-120 may have clinical benefits in patients with AMI; however, because the efficacy of AST-120 on kidney protection is controversial at present [21, 22], further studies are required to validate these hypotheses.

The present study has several limitations. The sample size that can be used is very small. Therefore, a statistically significant correlation between serum IS levels and serum NGAL levels could not be obtained. Although more patients were required, it was difficult to find appropriate patients with AMI at a single center. Based on the results of this study, we intended to shortly conduct an extensive, multicenter clinical study. Next, serum NGAL is one of the markers of kidney injury but which have some limitations. Serum NGAL could be affected not only kidney injury but also other factors such as inflammation. In this study, we could not measure serum NGAL levels and other surrogate markers such as urinary NGAL, KIM-1, or L-FABP in healthy subjects. Furthermore, we could not elucidate the mechanisms causing elevated serum IS levels in AMI from the results of this study. However, we speculate several possibilities based on previous studies [23-26]. First, alteration of intestinal flora can be one of the mechanisms involved. The intestinal flora was controlled by neurophysiological conditions and catecholamine secretion from the host [23]. Changes in these factors alter the intestinal flora within a few hours [24]. Hence, highstress conditions induced by MI may possibly alter the intestinal flora, leading to an increased indole synthesis. Second, SULT1A1 disorder could also be one of the mechanisms involved. SULT1A1 is a rate-limiting IS enzyme [18]. Recent experimental studies have reported that glucocorticoid and AKI increased SULT1A1 expression $[25,26]$. Critical illnesses, such as MI, may affect SULT1A1 expression. Since we could not confirm these changes in the present study, further studies are required in the future.

\section{Conclusion}

This result of this novel study, that focuses on IS in patients with AMI, suggests that serum IS increases in patients with AMI independent of the kidney function and that IS may be related with kidney injury. Overall, IS may be one of the crucial factors linked to CVD and kidney injury.

\section{Abbreviations}

AKI: Acute kidney injury; AMI: Acute myocardial infarction; BMI: Body mass index; Ca-blocker: Calcium channel blocker; CK: Creatine kinase; CKD: Chronic kidney disease; CK-MB: Creatine kinase-MB; CRP: C-reactive protein; CVD: Cardiovascular disease; eGFR: Estimated glomerular filtration rate; IS: Indoxyl sulfate; KIM-1: Kidney injury molecule-1; L-FABP: Liver-type fatty acid-binding protein; LVEF: Left ventricular ejection fraction; MI: Myocardial infarction; NGAL: Neutrophil gelatinase-associated lipocalin; NGSP: National Glycohemoglobin Standardization Program; NT-pro BNP: N-terminal pro-Btype natriuretic peptide; RAS-I: Renin-angiotensin system inhibitor

\section{Acknowledgements}

The authors thank Dr. Masahito Kawata (Division of Cardiology, Akashi Medical Center) for recruiting the study participants. 


\section{Authors' contributions}

SW, HF, KK, KW, SG, and SS participated in the design and coordination of the study. SW contributed to the data acquisition, data analysis, and manuscript writing. HF and SN contributed to the supervision or mentorship. All authors have read and approved the final manuscript.

\section{Funding}

This study was partly supported by the Fund of Kidney Disease Research from Hyogo Prefecture Health Promotion Association.

\section{Availability of data and materials}

Please contact the corresponding author for data requests.

\section{Ethics approval and consent to participate}

This study was prospectively conducted in accordance with the Declaration of Helsinki, and the study protocols were approved by the appropriate Institutional Review Committee (no. 27-7). Informed consent was obtained from all patients included in the study.

\section{Consent for publication}

Not applicable

\section{Competing interests}

The authors declare that they have no competing interests.

\section{Author details}

'Division of Nephrology and Kidney Center, Kobe University Graduate School of Medicine, 7-5-2, Kusunoki-cho, Chuo-ku, Kobe, Hyogo 650-0017, Japan. ${ }^{2}$ Department of Internal Medicine, Akashi Medical Center, 743-33, Ookubo-cho Yagi, Akashi, Hyogo 674-0063, Japan.

Received: 21 March 2019 Accepted: 11 June 2019 Published online: 03 July 2019

\section{References}

1. Sarnak MJ, Levey AS, Schoolwerth AC, Coresh J, Culleton B, Hamm LL, McCullough PA, Kasiske BL, Kelepouris E, Klag MJ, Parfrey P, Pfeffer M, Raij L, Spinosa DJ, Wilson PW. Kidney disease as a risk factor for development of cardiovascular disease: a statement from the American Heart Association Councils on Kidney in Cardiovascular Disease, High Blood Pressure Research, Clinical Cardiology, and Epidemiology and Prevention. Circulation. 2003;108: 2154-69.

2. Go AS, Chertow GM, Fan D, McCulloch CE, Hsu CY. Chronic kidney disease and the risks of death, cardiovascular events, and hospitalization. N Engl J Med. 2004:351:1296-305

3. Parikh CR, Coca SG, Wang Y, Masoudi FA, Krumholz HM. Long-term prognosis of acute kidney injury after acute myocardial infarction. Arch Intern Med. 2008:168:987-95.

4. Wright RS, Reeder GS, Herzog CA, Albright RC, Williams BA, Dvorak DL, Miller WL, Murphy JG, Kopecky SL, Jaffe AS. Acute myocardial infarction and renal dysfunction: a high-risk combination. Ann Intern Med. 2002; 137:563-70.

5. Goldberg A, Kogan E, Hammerman H, Markiewicz W, Aronson D. The impact of transient and persistent acute kidney injury on long-term outcomes after acute myocardial infarction. Kidney Int. 2009:8:900-6.

6. Niwa T, Ise M. Indoxyl sulfate, a circulating uremic toxin, stimulates the progression of glomerular sclerosis. J Lab Clin Med. 1994;124:96-104.

7. Miyazaki T, Ise M, Hirata M, Endo K, Ito Y, Seo H, Niwa T. Indoxyl sulfate stimulates renal synthesis of transforming growth factor-beta 1 and progression of renal failure. Kidney Int Suppl. 1997;63:S211-4.

8. Lekawanvijit S, Adrahtas A, Kelly DJ, Kompa AR, Wang BH, Krum H. Does indoxyl sulfate, a uraemic toxin, have direct effects on cardiac fibroblasts and myocytes? Eur Heart J. 2010;31:1771-9.

9. Yamamoto $H$, Tsuruoka $S$, loka $T$, Ando $H$, Ito C, Akimoto T, Fujimura A, Asano $Y$, Kusano E. Indoxyl sulfate stimulates proliferation of rat vascular smooth muscle cells. Kidney Int. 2006;69:1780-5.

10. Adijiang A, Goto S, Uramoto S, Nishijima F, Niwa T. Indoxyl sulphate promotes aortic calcification with expression of osteoblast-specific proteins in hypertensive rats. Nephrol Dial Transplant. 2008;23:1892-901.
11. Fujii H, Yonekura Y, Yamashita Y, Kono K, Nakai K, Goto S, Sugano M, Goto S, Fujieda A, Ito Y, Nishi S. Anti-oxidative effect of AST-120 on kidney injury after myocardial infarction. Br J Pharmacol. 2016;173:1302-13.

12. Thygesen K, Alpert JS, White HD. Joint ESC/ACCF/AHAMHF Task Force for the Redefinition of Myocardial Infarction. Universal definition of myocardial infarction. Eur Heart J. 2007;28:2525-38.

13. Matsuo S, Imai E, Horio M, Yasuda Y, Tomita K, Nitta K, Yamagata K, Tomino Y, Yokoyama H, Hishida A. Collaborators developing the Japanese equation for estimated GFR. Revised equations for estimated GFR from serum creatinine in Japan. Am J Kidney Dis. 2009;53:982-92.

14. Bolignano D, Lacquaniti A, Coppolino G, Donato V, Campo S, Fazio MR, Nicocia G, Buemi M. Neutrophil gelatinase-associated lipocalin (NGAL) and progression of chronic kidney disease. Clin J Am Soc Nephrol. 2009;4:337-44.

15. Marenzi G, Cosentino N, Bartorelli AL. Acute kidney injury in patients with acute coronary syndromes. Heart. 2015;101:1778-85.

16. Niwa T, Shimizu H. Indoxyl sulfate induces nephrovascular senescence. J Ren Nutr. 2012;22:102-6.

17. Watanabe H, Miyamoto $Y$, Otagiri M, Maruyama T. Update on the pharmacokinetics and redox properties of protein-bound uremic toxins. J Pharm Sci. 2011;100:3682-5.

18. Banoglu E, King RS. Sulfation of indoxyl by human and rat aryl (phenol) sulfotransferases to form indoxyl sulfate. Eur J Drug Metab Pharmacokinet. 2002;27:135-40.

19. Shimazu S, Hirashiki A, Okumura T, Yamada T, Okamoto R, Shinoda N, Takeshita K, Kondo T, Niwa T, Murohara T. Association between indoxyl sulfate and cardiac dysfunction and prognosis in patients with dilated cardiomyopathy. Circ J. 2013;77:390-6.

20. Lekawanvijit S, Kumfu S, Wang BH, Manabe M, Nishijima F, Kelly DJ, Krum H, Kompa AR. The uremic toxin adsorbent AST-120 abrogates cardiorenal injury following myocardial infarction. PLoS One. 2013;8:e83687.

21. Akizawa T, Asano Y, Morita S, Wakita T, Onishi Y, Fukuhara S, Gejyo F, Matsuo S, Yorioka N, Kurokawa K, CAP-KD Study Group. Effect of a carbonaceous oral adsorbent on the progression of CKD: a multicenter, randomized, controlled trial. Am J Kidney Dis. 2009;54:459-67.

22. Schulman G, Agarwal R, Acharya M, Berl T, Blumenthal S, Kopyt N. A multicenter, randomized, double-blind, placebo-controlled, dose-ranging study of AST-120 (Kremezin) in patients with moderate to severe CKD. Am J Kidney Dis. 2006;47:565-77.

23. Lyte M, Bailey MT. Neuroendocrine-bacterial interactions in a neurotoxininduced model of trauma. J Surg Res. 1997;70:195-201.

24. Lyte M, Frank CD, Green BT. Production of an autoinducer of growth by norepinephrine cultured Escherichia coli O157:H7. FEMS Microbiol Lett. 1996;139:155-9.

25. Duanmu Z, Kocarek TA, Runge-Morris M. Transcriptional regulation of rat hepatic aryl sulfotransferase (SULT1A1) gene expression by glucocorticoids. Drug Metab Dispos. 2001;29:1130-5.

26. Kusumoto M, Kamobayashi H, Sato D, Komori M, Yoshimura M, Hamada A, Kohda Y, Tomita K, Saito H. Alleviation of cisplatin-induced acute kidney injury using phytochemical polyphenols is accompanied by reduced accumulation of indoxyl sulfate in rats. Clin Exp Nephrol. 2011;15:820-30.

\section{Publisher's Note}

Springer Nature remains neutral with regard to jurisdictional claims in published maps and institutional affiliations.

Ready to submit your research? Choose BMC and benefit from:

- fast, convenient online submission

- thorough peer review by experienced researchers in your field

- rapid publication on acceptance

- support for research data, including large and complex data types

- gold Open Access which fosters wider collaboration and increased citations

- maximum visibility for your research: over $100 \mathrm{M}$ website views per year

At $\mathrm{BMC}$, research is always in progress.

Learn more biomedcentral.com/submissions 